\title{
Exploring the Positive Potentials of Diverse European Youth: What Makes Individual and Contextual Thriving Possible?
}

Commentary

\author{
Laura Ferrer-Wreder' and Sabina Kapetanovic ${ }^{1,2}$ \\ 'Stockholm University, Sweden \\ ${ }^{2}$ University West, Trollhättan, Sweden
}

\section{Exploring the Positive Potentials of Diverse European Youth: What Makes Individual and Contextual Thriving Possible?}

Many of today's young people are questioning the status quo as it relates to the care of our planet and its future, as well as actualizing in deeds and not just words greater equality among people. The study of adolescence today also needs a focus that can capture the present generation's unique strengths and vast potentials to deliver on what prior generations have only been able to just begin to talk about and have long struggled to realize. Since the 1990s, the study of adolescence has built up the concepts, tools, and knowledge that have shifted our conception about adolescents away from an expectation of inherent problems, danger and dysfunction to a refocusing on the whole person, which demands a vigorous investigation into the positive potentials of youth collectively as a generation and as diverse individuals on their own terms (Wiium \& Dimitrova, 2019).

The chapters in this book are at the forefront of the contemporary study of adolescence, which is more holistic and contextualized than in the past (e.g., Desie, 2020; Wiium \& Dimitrova, 2019). This book provides novel and valuable insights into the specific instances in which young people not only just survive and adapt but also thrive. Chapters within this book offer several examples of the strengths of young people (i.e., positive youth development, PYD) in terms of empirical evidence about PYD from youth living in Norway, Kosovo, Spain, and Slovenia (see Chapters 1, 2, 3, 4, 6 and 
7). For example, in Chapter 1, a study with adolescents in Norway indicated that internal and external assets were connected to thriving indicators. Being committed to learning, having positive values, as well as experiencing empowerment and spending time in organized activities were particularly important to thriving in this study which is situated in the wider youth development context of Norway (e.g., adolescents growing up amidst socio-cultural values that emphasize individual accomplishment, equality, rights of youth, care for others and the environment; see Chapter 1). These empirical examples from different regions of Europe are also complemented by commentaries and reviews that are highly relevant to the contemporary European context of youth development as a whole (see Chapters 5, 8, and 9).

\section{What Does It Mean to Thrive?}

This book is about the positive potentials of young people in Europe, but what does it really mean to thrive for today's young person living in Slovenia, Kosovo, Spain, or Norway, or in other parts of Europe? From the standpoint of psychology as a discipline, for humans of all ages, thriving is considered to involve individuals accomplishing developmental and/or socio-cultural tasks (i.e., these can be considered as indicators of performance), as well as experiences of subjective states that could include feeling good about oneself or happiness about one's life (Brown, Arnold, Fletcher, \& Standage, 2017). Thus, thriving represents a state of being as well as process of change; and that both accomplishment/performance and positive subjective feelings/experiences are present when people thrive (Brown et al., 2017). Thriving can occur across time and within interconnected contexts of development, such as at home, school, in one's neighbourhood and culture. Further, that thriving can be experienced across several domains of one's life or can be limited to a particular life domain(s), and can be experienced at any time and is not tied necessarily to adverse events (Brown et al., 2017).

This conceptualization implies that how thriving presents itself across individuals can differ and is closely tied to and has meaning within the context of one's life. The findings of several of the chapters in book are consistent with the heterogeneity of PYD when it is studied across contexts, in varied parts of the world (e.g., Wiium \& Dimitrova, 2019). There are commonalities (e.g., consider findings in Chapters 1 and 3, on the importance of commitment to learning and positive values), but there is also likely to be 
differences and a need for testing the character and intensity of how PYD presents itself one relative to another setting for youth development (e.g., see Chapter 4). Some of the chapters in this book directly address what thriving can be like for youth who are living in different parts of Europe (e.g., see Chapters 1, 2, 3). In these cases, thriving is conceptualized in ways that are consistent with main theoretical views of PYD such as those put forward by Benson and Scales (2009), namely thriving indicators such as school success, maintenance of physical health. Other works in this book focus on the feeling/subjective experience part of thriving, such as youths' view of their own well-being and life satisfaction.

Yet, thriving does not happen in a vacuum. Thriving involves a dynamic and reciprocal interplay between individuals and their contexts, as people move towards desired goals (Lerner et al., 2013). Thriving is well explained from the vantagepoint of several different developmental systems perspectives (e.g., Magnusson \& Mahoney, 2003; Overton, 2015), in which individuals (including youth) are active agents in the world, with in some cases altruistic and prosocial capacities, and have the possibility to move their own life trajectory in beneficial directions, while also interacting in a bidirectional manner with the contexts that provide opportunities for personal growth (Scales, Benson, Leffert, \& Blyth, 2000; Scales, Benson, \& Roehlkepartain, 2011; Lerner, 1984).

Given the dynamic nature of development in context, youth who have abundant opportunities to thrive within their contexts are likely to be committed and involved civically which contributes to the social good (Lerner et al., 2013). There is thus a striking interplay between adolescents and their contexts which makes both individual and contextual thriving possible. By reading about the numerous examples in the various chapters in this book, the reader learns vital information about the conditions that make it more or less likely that young people will thrive, and how the socio-cultural and other developmental contexts come into play as young people develop. In sum, the focus of this book overall is rightly on documenting thriving as well as individual and contextual assets that make thriving more likely.

This book also provides ample examples of the complexity of what is meant, when we talk about the context of youth development. Consistent with Bronfenbrenner's bioecological theory (Bronfenbrenner \& Morris, 2006) where proximal processes, the individual in all of its complexity, as well as micro and macro contexts in the wider current of time/history (i.e., the PPCT-model) simultaneously influence human development, youth 
thriving would have an impact across contexts. While micro contexts contain close systems such as family and school, macro contexts refer to wider and more distal systems that involve for example the political situation, economy, and the society as a whole. Thus, the context is an important actor with bearing on young people's development, involving the developmental assets (individual and contextual) which provide youth with possibilities to thrive (Wiium \& Dimitrova, 2019).

Further, the synergy between context and thriving is not simple. Depending on the cultural, political, and economic situation within the macro context, thriving could be more, or less straightforward. Cultural, political as well as economic systems have importance to young people's goals, motivations, and developmental and life prospects. The contextual assets available that could serve as a life line towards thriving could be plentiful or in short supply. Indeed, young people living in low- and middle-income countries (LAMICs) often have fewer opportunities and resources to achieve their goals, given the precarious situation and limits on socioeconomic development in many countries (United Nations World Youth Report, 2020). For example, in a study of Egyptian and Roma adolescents living in Albania, participants perceived an overall low availability of developmental assets, which in turn was viewed as posing additional challenges to participants' development (Miconi et al., 2021). Lack of developmental assets was particularly evident during the time period in which this study was conducted, namely during the Covid-19 pandemic, which was viewed as compounding pre-existing structural issues such as high unemployment and discrimination, and local challenges experienced by participants such as violence in their neighbourhoods and/or schools (Miconi et al., 2021).

\section{Innovations and the Call for Interventions and Generative Policy}

In terms of innovations, chapters in this book represent important advances on several different fronts. Several chapters are forward looking, for example, in terms of conducting the theoretical/empirical work that is vital to advancing the PYD field, such as including different theoretical constructs/ measures and traditions together within the same study (e.g., see Chapters 2 and 4). Other chapters add novel aspects of positive development that have been overlooked in the existing predominant frameworks of PYD (e.g., see Chapter 6 in regards to its consideration of humor and gratitude; see 
Chapter 8 which expands the PYD construct of contact/connection, but in the context of interventions aimed at reducing ethnic prejudice in schools). While still other chapters expand our understanding of the ways that PYD can be measured using various tools (e.g., Chapter 4) and how pre-existing, large scale and well-established youth surveys such as the Programme for international student assessment (PISA; OECD, 2021; see Chapter 7) can be leveraged to study PYD.

In order for youth to thrive, actions from society are needed. Working with interventions for youth and their contexts that would make young people oriented toward thriving is vital, and this type of next step in the PYD field, and such efforts can build off of the knowledge presented in this book. PYD interventions can foster strengths and positive potentials as the sole goal of intervention, boosting strengths for their own sake. Yet, we see in several cases that problems and strengths can but do not always have to intersect (Taylor, Oberle, Durlak, \& Weissberg, 2017). What are the strengths and potentials linked to both thriving and the reduction of problems? This is vital knowledge that will advance the study of adolescence into the future (Brooks-Gunn \& Roth, 2014).

Further, young people themselves are key actors in the dynamic system of human development. Working systematically to build on and support the internal assets of youth and to create asset rich contexts is a wise investment in the current new generation of young people who will face substantial, future globally shared challenges (e.g., climate change, sweeping changes in technology). Well informed and authentically generative social policy, context and individual oriented PYD interventions that foster strengths as well as have the potential to reduce problems are vitally important so that there can be a successful interplay between youth and their contexts and, above all, support young people so that many more individuals can thrive and act in an empowered and beneficial way that leads to the long-term well-being of our global community, well into the future.

\section{References}

Benson, P. L., \& C. Scales, P. (2009). The definition and preliminary measurement of thriving in adolescence. The Journal of Positive Psychology, 4, 85104. https://doi.org/10.1080/17439760802399240

Bronfenbrenner, U., \& Morris, P. A. (2006). The bioecological model of human development. In W. Damon (Series Ed.) \& R. M. Lerner (Vol. Ed.), 
Handbook of child psychology: Theoretical models of human development (pp. 793-828). Wiley.

Brooks-Gunn, J. \& Roth, J. (2014). Invited commentary: Promotion and prevention in youth development: Two sides of the same coin? Journal of Youth and Adolescence, 43, 1004-1007. https://doi.org/10.1007/s10964-014-0122-y

Brown, D. J., Arnold, R., Fletcher, D., \& Standage, M. (2017). Human thriving: A conceptual debate and literature review. European Psychologist, 22, 167179. https://doi.org/10.1027/1016-9040/aooo294

Desie, Y. (2020). From surviving to thriving: Characterizing positive youth development among youth in Ethiopia. International Journal of Adolescence and Youth, 25, 200-209. https://doi.org/10.1080/02673843.2019.1608272

Lerner, J. V., Bowers, E. P., Minor, K., Lewin-Bizan, S., Boyd, M. J., Mueller, M. K., Schmid, K. L., Napolitano, C. M., \& Lerner, R. M. (2013). Positive Youth Development: Processes, Philosophies, and Programs. In R. M. Lerner, M. A. Easterbrooks \& J. Mistry (Eds.), Developmental Psychology, Handbook of Psychology (pp. 365-392). Editor-in-chief: I. B. Weiner. Hoboken: Wiley.

Magnusson, D., \& Mahoney, J. L. (2003). A holistic person approach for research on positive development. In L. G. Aspinwall, \& U. M. Staudinger (Eds.), A psychology of human strengths: Fundamental questions and $f u-$ ture directions for a positive psychology (pp. 227-243). Washington, DC: American Psychological Association. https://doi.org/10.1037/10566-016

Miconi, D., Dervishi, E., Wiium, N., Johnson-Lafleur, J., Ibrahimi, S., \& Rousseau, C. (2021). Egyptian and Roma adolescents' perspectives on their developmental assets in Albania during the COVID-19 pandemic. Journal of Research on Adolescence, 31, 576-594. https://doi.org/10.1111/ jora.12665

OECD. (2021). Programme for international student assessment. https://www. oecd.org/PISA/

Overton, W. F. (2015). Processes, relations, and relational-developmental-systems. In W. F. Overton, P. C. M. Molenaar \& R. M. Lerner (Eds.), 7th ed.; Handbook of child psychology and developmental science: Theory and method (pp. 9-62). Hoboken, NJ: John Wiley \& Sons. https://doi. org/10.1002/9781118963418.childpsy102

Scales, P. C., Benson, P. L., Leffert, N., \& Blyth, D. A. (200o). Contribution of developmental assets to the prediction of thriving among adolescents. Applied Developmental Science, 4, 27-46. https://doi.org/10.1207/ S1532480XADSo401_3 
Scales, P. C., Benson, P. L., \& Roehlkepartain, E. C. (2011). Adolescent thriving: The role of sparks, relationships, and empowerment. Journal of Youth and Adolescence, 40, 263-277. https://doi.org/10.1007/s10964-010-9578-6

Taylor, R. D., Oberle, E., Durlak, J. A., \& Weissberg, R. P. (2017). Promoting positive youth development through school-based social and emotional learning interventions: A meta-analysis of follow-up effects. Child Development, 88, 1156-1171. https://doi.org/10.1111/cdev.12864

United Nations World Youth Report. (2020). Youth social entrepreneurship and the 2030 agenda. https://www.un.org/development/desa/youth/wp-content/uploads/sites/21/2020/07/2020-World-Youth-Report-FULL-FINAL. pdf

Wiium, N., \& Dimitrova, R. (2019). Positive youth development across cultures: Introduction to the special issue. Child \& Youth Care Forum, 48, 147-153. https://doi.org/10.1007/s10566-019-09488-7 